\title{
Assessment of environmental flow requirements of damodar river basins by using flow duration indices method - a case study
}

\begin{abstract}
River systems attain zero flow due to water retaining structure construction, hydropower generating structures and bridge construction. This possesses a tremendous threat to the environment, ecology and aquatic life of the river systems. Therefore, environmental flow assessment is of prime importance to analyze the natural flow regime of the river which is required to be maintained for the sustainability of the ecosystem. In the present study, the environmental flow of the Damodar River Basin has been assessed by using the Flow Duration Curve (FDC). Out of the 41 year of flow data, the $90 \%$ exceedence probability of flow was attained in the year of 2009 2010 and corresponding flow was observed to be as 122 cumec approx. This flow will persist for $90 \%$ of the time throughout the year.
\end{abstract}

Volume 2 Issue 3 - 2018

\author{
Satyajit Mitra, Ajai Singh \\ Department of Water Engineering and Management, Central \\ University of Jharkhand, Ranchi, Jharkhand, India \\ Correspondence: Ajai Singh, Department of Water \\ Engineering and Management, Central University of Jharkhand, \\ Ranchi, Jharkhand, India, Email ajai.singh@cuj.ac.in
}

Received: August 21, 2017| Published: May 03, 2018

Keywords: environmental flow, flow duration curve, Damodar river

\section{Introduction}

Flow is an important variable because it affects greatly the aquatic habitat, river morphology, biotic life, river connectivity and water quality. ${ }^{1}$ Environmental flow (E-flows) is now not a new concept and scientist/researchers and even water resources planner are giving due importance to this term. As the natural flow is not maintained in the river especially in the downstream zone, the aquatic habitats and the local stakeholder relying on river water for their daily activities are affected. Environmental flow regulations were not appropriately incorporated during the river project formulation period and therefore river basin projects immensely affected the river's flow regime, downstream water availability, water quality and riverine ecosystems. E-flows are the basic flows that are needed to maintain the aquatic ecosystems. It is a flow regime that is capable of sustaining a total set of habitats and ecosystem processes within it. E-flows are needed for the various other purposes also. It maintains the river flow conditions and maintains desirable flow which supports the basic living conditions of the people. It sustains both land and water ecosystems and recharges the groundwater. Studies have shown that all elements of a flow regime, including high, medium and low flows, are important from the ecosystem point of view. ${ }^{2}$ Specifically, high flows are necessary for channel flushing, maintaining floodplain connectivity and riparian vegetation; medium flows help in fish growth and migration, and low flows are important in river connectivity and maintaining water quality. ${ }^{3}$ The perennial flow of water is the best evidence that the river exists.

Present study focuses on river Damodar which flows across the Indian states of West Bengal and Jharkhand. Both the states are rich in mineral resources and are home to large scale mining and industrial activities. Earlier known as the Sorrow of Bengal because of its intensified floods in the plains of West Bengal, the Damodar and its tributaries have been cascaded with the construction of several dams. It is one of the most polluted rivers of India. The Barakar, the most important tributary of the Damodar, originates near Padma in Hazaribagh district and flows through Jharkhand before meeting the
Damodar near Dishergarh, a neighborhood in Asansol, West Bengal. The Damodar and the Barakar trifurcates the Chota Nagpur plateau. The initial focus of the DVC was flood control, irrigation, generation, transmission and distribution of electricity, eco-conservation and afforestation. The dams in the valley have a capacity to moderate peak floods of 7,100 to $18,400 \mathrm{~m}^{3} / \mathrm{s}$. DVC has created irrigation potential of $3,640 \mathrm{~km}^{2}$. The rivers pass through hilly areas with great force, sweeping away whatever lies in their path. Several dams have been constructed in the valley for the generation of hydroelectric power. It is modeled on the Tennessee Valley Authority of the United States. ${ }^{4}$

A hydrological flow method was developed that required past flow data. ${ }^{5}$ It requires data of presence or absence of fish in the stream and a continuous 20 years of average daily flow. It was mainly developed to meet the needs of regulations governing water division, mainly for small hydropower projects in British Columbia. A variant of the FDC method was proposed for data deficient situation like in India. ${ }^{6}$ The method is based on a reference FDC that focuses on monthly discharge time series of unregulated river and calculates how much flow can be modified. The FDCs are then represented by a table of flows corresponding to 17 fixed percentage points $0.01,0.1,1.5,10$, $20,30,40,50,60,70,80,90,95,99,99.9,99.99$ percent to cover the entire range flows. The desired condition of river is named as EMC (environmental management class). Higher EMC requires more water with greater flow for maintenance of ecosystem. These EMCs are purely conceptual and not based on any empirical relationships. ${ }^{7}$ Desktop method was developed which mainly focused on natural historic stream flows. ${ }^{8}$ This method recommends 15 percent instantaneous reduction from natural flow, or, the lesser of either the natural flow or 80 percent exceedence natural flow based on weekly or monthly time basis. A number of methodologies are practiced worldwide to estimate E-flows. There are over 200 methodologies which are practiced to estimate E-flows but in India only a few prevalent methods are practiced. ${ }^{8}$ Generally the environmental flow estimation methods are classified into 4 broad categories such as Hydrological Methods, Hydraulic Rating Method, Habitat Simulation Methods and Holistic 
methods. In the present study, estimation of environmental flow of River Damoda at different gauging stations were carried out by using Flow Duration Curve in order to ensure proper availability of water to the downstream side of river.

\section{Materials and methods}

\section{Study area}

River Damodar originates in Chandwa village, Palamau district in the Chotanagpur plateau in the Jharkhand state in Eastern India and flows about $592 \mathrm{~km}$ eastwards through the states of Jharkhand and West Bengal. It has a number of tributaries and sub tributaries like Barakar, Konar, Jamunia, Ghari, Khadia, Bhera. The damodar basin spreads over an area of $23,370.98 \mathrm{~km}^{2}$. The geographical boundary of the basin lies between $22^{\circ} 5^{\prime}$ to $24^{0} 30^{\prime} \mathrm{N}$ latitude and $84^{\circ} 30^{\prime}$ to $88^{\circ} 15^{\prime} \mathrm{E}$ longitude and extends over 6 districts of Jharkhand and 5 districts of West Bengal. Location of Damodar River Basin is shown in Figure 1. Data were collected from eight sites in the lower stretch of the river from Jamalpur to Ramgarh. Coordinates of each sampling sites were recorded. The coordinates ranged from N 23030.0", E 87019.12" to

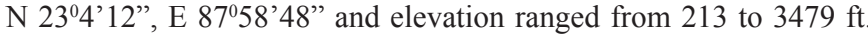
Figure 2 shows the location of gauging sites from where data were recorded and collected. Some parts of the state West Bengal and some parts of the state Jharkhand are involved. In this study, 41 years of monthly flow data for the periods $1972-73$ to $2012-13$ were used to develop Flow Duration Curve. The 41 years (1972- 2013) flow data were collected from DVC Maithon and CWC Maithon that mainly supervises and monitors the gauging sites of Damodar river. The basic data of all the 8 gauging stations are summarized.

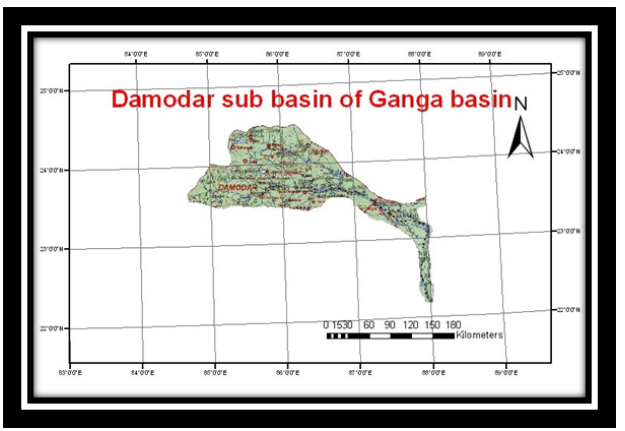

Figure I Damodar river basin (Source: DVC Maithon, 2003).

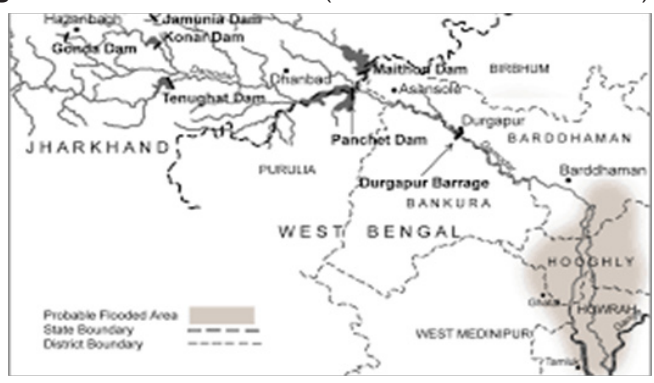

Figure 2 Tributaries and the gauging sites of Damodar basin.

\section{Flow Duration Curve (FDC)}

The Flow Duration Curve (FDC) is a cumulative frequency curve representing the percent of time during which the average discharge equaled to or exceeded a particular value at a given location. The FDC may represent the daily, weekly or monthly values of discharge. The discharge data were plotted on a logarithmic scale or percentages of total discharge. Chronological sequences of events are not taken into account. It is very useful when prepared using long term data ranging from 10 to 50 years. The method does not take into account the biological viewpoint because the biotas are largely affected by the flow variation and velocity. A common hydrological index is 7Q10. It defines the lowest flow recorded for the seven consecutive days within a 10 year return period. ${ }^{89} \mathrm{~A}$ variant of $7 \mathrm{Q} 10$ was used in Canada which was 7Q2. As it uses 2 year return period, it provided slightly greater threshold. The other two indices Q95 and Q90 (daily flows exceeding $95 \%$ and $90 \%$ of the time, respectively) are very popular and practiced in many countries. Hydrological variability at any place has mainly 5 main attributes such as Depth, Duration, Amplitude, Frequency and Timing. In the present study Q90 method was applied. The flow data were ranked in descending order. The exceedence probability of the event $\mathrm{P}$ was determined by the given formula:

$$
P=\frac{m}{n+1} \times 100
$$

Where,

$$
\begin{aligned}
& n=\text { no. of flow events } \\
& m=\text { ranking of the flow events }
\end{aligned}
$$

Q90 method defines the flow exceeded for $90 \%$ of the time. It allots the minimum flow for the aquatic environment and checks dischargeduration patterns of small streams. The water level flow should not fall below the water flow allotted by this method for a healthy balance to be maintained in the ecosystem.

\section{Results and discussions}

FDC index i.e. Q90 was applied. Q90 is attained in the year of 2009-10. Flow duration curve for 41 years of flow data was plotted with discharge in cumec on $\mathrm{x}$ axis and exceedence probability on $y$ axis (Figure 3). It is observed that $97.6 \%$ exceedence probability is achieved. Out of 41 years of data, the flow corresponding to $97.6 \%$ exceedence probability is 111.23 cumec of flow which will be available throughout the year and it is the E-flows of the study area. Below this if the flow goes then ecological imbalance will occur. Figure 4 indicates the flow duration curve that corresponds to Q90 flow duration index. Out of the 41 year of flow data, the $90 \%$ exceedence probability of flow is attained at the year of 2009-2010. And the corresponding flow in this year of 2009-2010 is 122 cumec approx. This flow will persist for $90 \%$ of the time throughout the year.

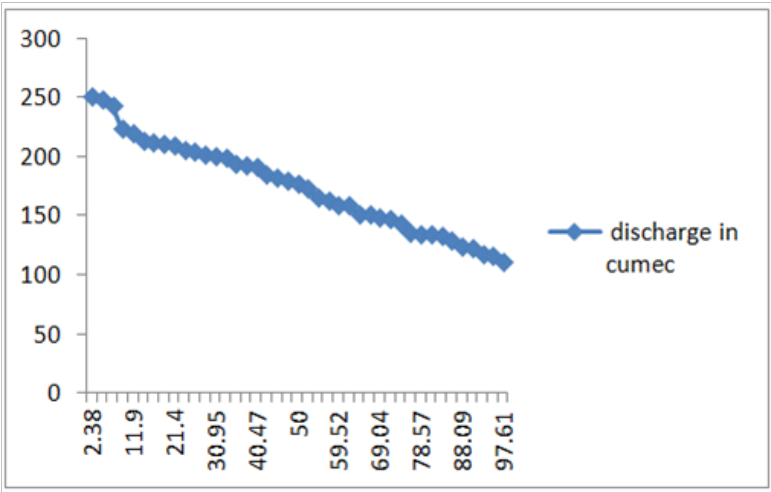

Figure 3 Flow duration curve of $4 \mathrm{I}$ years of flow events. 


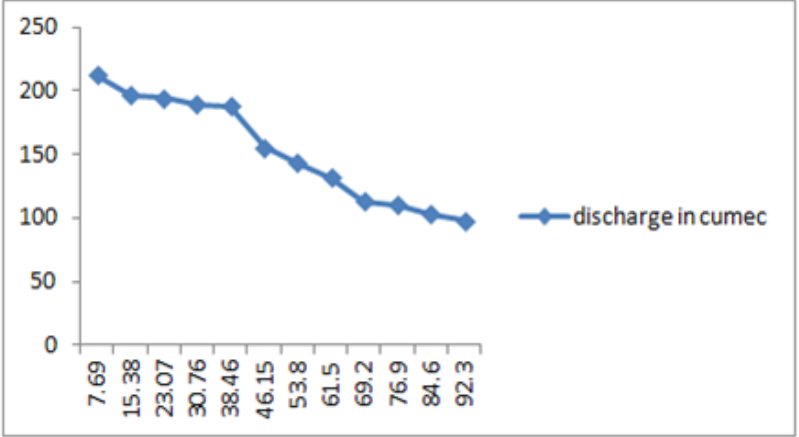

Figure 4 Flow duration curve corresponds to $\mathrm{Q} 90$ flow duration index

\section{Conclusion}

Flow Duration Curve Method was applied to estimate the environment flow in Damodar river with the data available in 8 gauging stations. FDC is the method that solely depends upon the flow data of the river basin. As Damodar is a rainfed river, FDC method is a wise option to assess the E-flows. Low flow duration index i.e. Q90 helps appropriately to get the 90 percentile flow even in worst case scenario. Out of the 41 year of flow data, the $90 \%$ exceedence probability of flow was attained in the year of 2009-2010 and corresponding flow was observed to be as 122 cumec approx. This flow will persist for $90 \%$ of the time throughout the year.

\section{Acknowledgements}

None.

\section{Conflict of interest}

The author declares there is no conflict of interest.

\section{References}

1. Karr JR. Biological integrity: a long-neglected aspect of water resource management. Ecol. 1991;1:66-84.

2. Richter BD, Baumgartner JV, Wigington R, et al. How much water does a river need?. Freshwater Biol. 1997;37:231-249.

3. Acreman MC. Environmental flows from dams; the Water Framework Directive. Eng Sustain. 2009;162(1):13-22.

4. Majumder M, Roy P, Mazumdar A. An Introduction and Current Trends of Damodar and Rupnarayan River Network. In: Jana B, Majumder M, editors. Impact of Climate Change on Natural Resource Management. Springer, 2010;110.

5. Hatfield TBC. Ministry of Environment Winter Flows Project. Canada: Final Report, Ecofish Research Ltd. Courtenay. 2012.

6. Smakhtin VU, Anputhas M. An assessment of environmental flow requirements of Indian river basins. Research report 107, IWMI. 2006;146.

7. Puckridge JT, Sheldon F, Walker KF, et al. Flow variability and the ecology of large rivers. Marine and Freshwater Research. 1998;49:55-72.

8. Tharme RE. A global perspective on environmental flow assessment: emerging trend in development and application for environmental flow methodologies for rivers. River Research and Application. 2003;19:397441.

9. Caissie D, El- Jabi, Bourgeois G. Instream flow evaluation by hydrologically based \& habitat preference techniques. Revue des Sciences de l'Eau. 1998;11(3):347-363. 